\title{
Development of a Simple Version of the 27-item Version of an Instrument to Measure Self-Efficacy for Social Participation of People with Mental IIIness
}

\author{
Mayo Hiroshima \\ Graduate School of Medicine, Kyoto University, Kyoto, Japan \\ E-mail: hiroshima.mayo.2x@kyoto-u.ac.jp \\ Manami Amagai \\ School of Nursing, National College of Nursing, Tokyo, Japan
}

Doi:10.5901/mjss.2013.v4n10p50

\begin{abstract}
Background: People with severe mental illness can now function better in their communities because of improved local mental health services. Nevertheless, a convenient short scale for evaluating their functioning would be useful. Purpose: We simplified the 27-item version of an instrument measuring self-efficacy for social participation in mentally ill individuals (SESP27), creating an abridged 10-item version (SESP10). The validity and reliability of the SESP10 were then assessed. Methods: We administered the SESP27, Rosenberg's Self-Esteem Scale, Norbeck's Social Support Scale, the Sense of Coherence Scale (13-item), and the 12-item General Health Questionnaire to 145 community-dwelling mentally ill people using a psychiatric service. We also assessed how satisfied subjects were with their lives and whether they had any life goals. To verify the reliability of the SESP10, the SESP27 was distributed to the same participants about 1 month after the first survey. By referring to the factor structure of the SESP27, 10 items that were found to have high loadings were selected and used to create the SESP10. Results: Confirmatory factor analysis showed that the SESP10 maintained the four-factor structure of the SESP27, with sufficient content validity; these factors were: "trust in social self" (2 items), "self-management" (3 items), "social adaptability" (2 items), and "mutual support" (3 items). Furthermore, the SESP10 had excellent internal consistency, test-retest reliability, and criterion validity. Conclusion: The validity and reliability of the SESP10 were confirmed. Because of its convenience, it can be widely applied to people with severe mental illness.
\end{abstract}

Keywords: self-efficacy, social participation, mentally illness

\section{Background}

Supporting individuals with mental illness is often about helping them participate in society in their own ways despite their chronic symptoms or disorders, rather than achieving complete cure of the disease. The primary factor that inhibits social participation in mentally ill people is the insufficiency of social support or governmental systems to help them integrate into society; however, their own individual factors cannot be ignored. This involves not only their impaired functions or abilities, but also their lack of self-efficacy (self-confidence) in social participation or community life. Lack of self-efficacy requires more attention as a factor that inhibits mentally ill people from engaging in social participation.

Accordingly, we developed an instrument to measure mentally ill people's level of self-efficacy (self-confidence) in social participation (SESP27). This scale is significant in that it can measure the effectiveness of psychiatric rehabilitation from the subjective perspectives of mentally ill individuals.

In recent years, even the people with severe mental illness have become able to live successfully in communities, because of 24-hour comprehensive services such as assertive community treatment (ACT), which provides mentally ill people with adequate healthcare, welfare, and employment. We believe that it would be beneficial and convenient to develop a simplified scale with good reliability and validity, and that is applicable to a wide range of mental disease levels, for measuring self-efficacy in social participation in mentally ill people.

The objective of this study is to abridge the original SESP27 for individuals with mental illness into a simplified 10item version. 


\section{Methods}

\subsection{Study period: May to December 2009.}

\subsection{Subjects}

We selected 164 mentally ill community-dwelling people who were using day hospitals in psychiatric medical institutions, local activity support centers, small workplaces for mentally ill people, working continuation support workshops, and related institutions.

\subsection{Measures}

\subsubsection{Basic characteristics of participants}

The specific items that we examined regarding participants' characteristics were gender, age, race, religion, diagnosis, history of hospitalization, duration of disease, housing condition, sociopsychological services currently used, employment status, etc.

\subsubsection{Evaluation of psychological symptoms}

Participants' psychological symptoms were evaluated as part of our assessment of their characteristics. To reduce the possible burden on participants, their psychological symptoms were evaluated using the Brief Psychiatric Rating Scale (BPRS) with the minimum number of items. Evaluations were conducted by trained psychiatric nursing specialists.

\subsubsection{SESP27}

In this survey, the original version of the SESP27 was used to measure the levels of self-efficacy in social participation of mentally ill people. We had developed this scale previously, and have already confirmed its reliability and validity (Amgai, Suzuki, Shibata, \& Tsai, 2012). This scale consisted of four subscales (27 items): "trust of social self" (8 items), "selfmanagement" (7 items), "social adaptability" (7 items), and "mutual support" (5 items). Subjects were asked how confident they currently felt about each item, which they rated on a 4-point scale, ranging from 3 ("I am confident") to 0 ("I am not confident"). Higher scores indicated greater confidence in social participation.

\subsubsection{Scales related to social participation}

We used Rosenberg's Self-Esteem Scale (Rosenberg, 1965), Norbeck's Social Support Scale (Japanese version, Maeda, Hata, \& Hata, 2003), the Sense of Coherence Scale (13-item Japanese version, Togari \& Yamazaki, 2005) and the 12-item General Health Questionnaire (Niiro \& Mori, 2001). Before using these related scales, we confirmed that they were available and obtained their developers' approval before using them.

Additionally, we included questions on how satisfied the subjects were with their lives and whether they had any life goals.

\subsection{Procedures}

\subsubsection{Selection of survey-cooperating facilities and invitation of participants}

People with mental illness are likely to exhibit greater vulnerability to stress than healthy people. In light of this, before asking for participants' cooperation in the survey, we explained the study purpose and all ethical considerations to staff members of facilities that had good relationships with us.

For recruitment, we asked staff members who had built good relationships with prospective participants to introduce them to us. Extreme caution was exercised to ensure that participants did not interpret our approach as coercion. The study content and ethical considerations were explained to participants, and those who agreed to participate were asked to sign the consent document. 


\subsection{Procedures}

The questionnaire was primarily self-administered, but we also interviewed participants who expressed the desire to be due to their impeding mental or physical conditions.

In order to verify the reliability of the newly developed abridged version of the SESP27, a questionnaire sheet consisting only of the abridged SESP scale for individuals with mental illness was distributed to the same participants about 1 month after the first questionnaire survey.

Mental conditions were assessed immediately after participants finished the first questionnaire survey. Psychiatric nursing specialists interviewed the participants to make these assessments. For this assessment, nurses exercised extreme caution to protect participants' privacy and avoided giving any impression of forcing the participants.

A cover was put on the questionnaire sheets so that the content could not be seen by others. After the survey, the questionnaire sheets were put in a drawstring envelope and carried to a designated collection site. The collected questionnaire sheets were put into a locked cabinet for preservation as soon as possible.

\subsection{Ethical considerations}

The present study was approved by the Ethics Committee of the Graduate School of Medicine, in the Faculty of Medicine at Kyoto University.

Our ethical considerations included respect for the will of the participants (including the voluntary nature of participation in the study and the possibility of withdrawing at any point), privacy protection (anonymity during the statistical analysis of questionnaire responses), the restriction of data usage to only the study, and the requirement of a signature on the consent form as evidence of participation.

\subsection{Data Analysis}

First, a principal component factor analysis with varimax rotation was performed on the 145 responses to the SESP27 scale. By referring to the factor structure of the SESP27, 10 items were selected from the items that were found to have high loadings in the above factor analysis, and used in the simplified version of the SESP scale (SESP10). Confirmatory factor analysis was performed to assess the validity of the SESP10.

To assess the reliability of the SESP10, we calculated the Cronbach's a coefficient of internal consistency and the test-retest reliability coefficient.

To assess the validity of the SESP10, the concurrent validity was determined by calculating the correlation coefficients between the total SESP10 score, the subscale scores, and the scores of other self-efficacy scales.

All statistical analysis was performed using SPSS for Windows $18.0 \mathrm{~J}$ (SPSS Inc., 2009).

\section{Results}

\subsection{Overview of participants}

The number of valid responses was 145 (88.4\%) from among 165 questionnaires distributed. Table 1 shows the breakdown of participants' characteristics. Although variations were observed in some areas-including gender, age, diagnosis, and severity of the conditions among the eight facilities-the distribution was generally similar, and therefore, these facilities were grouped into one for the subsequent analyses.

Table 1. Gender, age, diagnosis, and BPRS in each facility and in the total sample

\begin{tabular}{|c|c|c|c|c|c|c|c|}
\hline \multirow{2}{*}{ Institution } & \multirow{2}{*}{$\mathrm{N}$} & \multirow{2}{*}{$\begin{array}{c}\text { Sex } \\
\text { (Male) } \\
N(\%)\end{array}$} & \multirow{2}{*}{$\begin{array}{l}\text { Age } \\
\text { Mean } \\
(\mathrm{SD})\end{array}$} & \multicolumn{3}{|c|}{$\begin{array}{c}\text { Diagnoses } \\
N(\%)\end{array}$} & \multirow{2}{*}{$\begin{array}{c}\text { BPRS } \\
\text { Mean } \\
\text { (SD) }\end{array}$} \\
\hline & & & & Schizophrenia & Mood disorder & Others & \\
\hline 1 & 17 & $\begin{array}{c}15 \\
(88.2)\end{array}$ & $\begin{array}{l}36.1 \\
(9.7)\end{array}$ & $\begin{array}{c}13 \\
(86.7)\end{array}$ & $\begin{array}{c}0 \\
(0)\end{array}$ & $\begin{array}{c}2 \\
(13.3)\end{array}$ & $\begin{array}{c}33.6 \\
(11.3)\end{array}$ \\
\hline 2 & 8 & $\begin{array}{c}8 \\
(100)\end{array}$ & $\begin{array}{l}52.9 \\
(7.9)\end{array}$ & $\begin{array}{c}6 \\
(75.0)\end{array}$ & $\begin{array}{c}0 \\
(0)\end{array}$ & $\begin{array}{c}2 \\
(25.0)\end{array}$ & $\begin{array}{l}24.1 \\
(2.8)\end{array}$ \\
\hline
\end{tabular}




\begin{tabular}{|c|c|c|c|c|c|c|c|}
\hline 3 & 12 & $\begin{array}{c}6 \\
(50)\end{array}$ & $\begin{array}{l}36.8 \\
(6.6)\end{array}$ & $\begin{array}{c}11 \\
(91.7) \\
\end{array}$ & $\begin{array}{c}1 \\
(8.3)\end{array}$ & $\begin{array}{c}0 \\
(0)\end{array}$ & - \\
\hline 4 & 6 & $\begin{array}{c}1 \\
(20)\end{array}$ & $\begin{array}{c}16.5 \\
(16.1)\end{array}$ & $\begin{array}{c}4 \\
(100)\end{array}$ & $\begin{array}{c}0 \\
(0)\end{array}$ & $\begin{array}{c}0 \\
(0)\end{array}$ & $\begin{array}{l}38.0 \\
(9.7)\end{array}$ \\
\hline 5 & 3 & $\begin{array}{c}2 \\
(66.7)\end{array}$ & $\begin{array}{l}42.0 \\
(4.4)\end{array}$ & $\begin{array}{c}3 \\
(100)\end{array}$ & $\begin{array}{c}0 \\
(0)\end{array}$ & $\begin{array}{l}0 \\
(0)\end{array}$ & $\begin{array}{l}40.0 \\
(5.6)\end{array}$ \\
\hline 6 & 21 & $\begin{array}{c}11 \\
(55.0)\end{array}$ & $\begin{array}{c}48.4 \\
(10.1)\end{array}$ & $\begin{array}{c}13 \\
(65.0)\end{array}$ & $\begin{array}{c}2 \\
(10.0)\end{array}$ & $\begin{array}{c}2 \\
(10.0)\end{array}$ & $\begin{array}{l}15.8 \\
(8.2)\end{array}$ \\
\hline 7 & 58 & $\begin{array}{c}37 \\
(67.3)\end{array}$ & $\begin{array}{l}33.5 \\
(8.5)\end{array}$ & $\begin{array}{c}36 \\
(62.1)\end{array}$ & $\begin{array}{c}2 \\
(3.4)\end{array}$ & $\begin{array}{c}14 \\
(24.1)\end{array}$ & $\begin{array}{c}35.4 \\
(11.6)\end{array}$ \\
\hline 8 & 15 & $\begin{array}{c}7 \\
(46.7)\end{array}$ & $\begin{array}{c}39.9 \\
(10.5)\end{array}$ & $\begin{array}{c}12 \\
(72.6)\end{array}$ & $\begin{array}{c}1 \\
(6.7)\end{array}$ & $\begin{array}{c}1 \\
(6.7)\end{array}$ & - \\
\hline total & 140 & $\begin{array}{c}87 \\
(64.4)\end{array}$ & $\begin{array}{c}37.6 \\
(11.9)\end{array}$ & $\begin{array}{c}98 \\
(72.6)\end{array}$ & $\begin{array}{c}6 \\
(4.4)\end{array}$ & $\begin{array}{c}21 \\
(15.6)\end{array}$ & $\begin{array}{c}31.1 \\
(12.9)\end{array}$ \\
\hline
\end{tabular}

\subsection{Item selection and confirmatory factor analysis based on the factor analysis results of the SESP27}

Table 2 shows the results of the factor analysis of the SESP27 (principal component factor analysis, varimax rotation). There were five factors, which mostly retained the four original subscales of "trust in social self," "self-management," "social adaptability," and "mutual support."

By referring to the factor structure of the SESP27 (four subscales), 10 items (shown by in Table 2) were selected from the items that were found to have high loadings in the above factor analysis. These 10 items form the SESP10.

We performed a confirmatory factor analysis to assess the validity of the SESP10, and found that the factor structure consisting of four subscales was maintained, demonstrating full content validity (Table 3).

Table 2. Results of the factor analysis of the SESP27

\begin{tabular}{|c|c|c|c|c|c|}
\hline Item & Factor 1 & Factor 2 & Factor 3 & Factor 4 & Factor 5 \\
\hline I can do things without worry. & 0.764 & 0.168 & 0.235 & 0.098 & 0.329 \\
\hline I can break free from past failures. & 0.627 & 0.170 & 0.161 & 0.159 & 0.248 \\
\hline $\begin{array}{l}\text { I can associate with others even when I feel tired and } \\
\text { nervous. }\end{array}$ & 0.602 & 0.407 & 0.126 & 0.310 & 0.017 \\
\hline I feel I am a valuable person in society. & 0.599 & 0.186 & 0.528 & 0.300 & 0.037 \\
\hline I can be useful for something or to someone. & 0.595 & 0.238 & 0.248 & 0.412 & 0.204 \\
\hline I can make decisions on my own judgment. & 0.529 & 0.420 & 0.098 & 0.351 & 0.403 \\
\hline I can keep up with the changes in society. & 0.470 & 0.320 & 0.342 & 0.061 & 0.467 \\
\hline I can control my physical condition in my daily life. & 0.165 & 0.736 & 0.300 & 0.252 & 0.229 \\
\hline I can control my mood in my daily life. & 0.378 & 0.598 & 0.299 & 0.251 & 0.130 \\
\hline I have the physical strength to live as I would like. & 0.192 & 0.581 & 0.253 & 0.195 & 0.385 \\
\hline $\begin{array}{l}\text { I can make my own decisions about my schedule in } \\
\text { daily life. }\end{array}$ & 0.264 & 0.542 & 0.344 & 0.252 & 0.177 \\
\hline $\begin{array}{l}\text { I am aware of the social resources that I can use } \\
\text { when I am in trouble. }\end{array}$ & 0.242 & 0.509 & 0.198 & 0.227 & 0.293 \\
\hline $\begin{array}{l}\text { I can get by even when I feel I have more difficulties } \\
\text { (than others) in life. }\end{array}$ & 0.380 & 0.483 & 0.170 & 0.199 & 0.308 \\
\hline $\begin{array}{l}\text { I am capable of having a social position I can } \\
\text { describe to others. }\end{array}$ & 0.192 & 0.288 & 0.732 & 0.133 & 0.141 \\
\hline I can find work or activities that suit me. & 0.208 & 0.192 & 0.526 & 0.189 & 0.472 \\
\hline In the future, I can live a life that will satisfy myself. & 0.181 & 0.432 & 0.490 & 0.348 & 0.204 \\
\hline $\begin{array}{l}\text { I have work that I am used to and a comfortable } \\
\text { environment, and I feel that I will do all right. }\end{array}$ & 0.186 & 0.278 & 0.473 & 0.079 & 0.472 \\
\hline If I try, I have the power to change society. & 0.260 & 0.219 & 0.430 & 0.429 & 0.177 \\
\hline $\begin{array}{l}\text { My actions and social participation are encouraging to } \\
\text { others. }\end{array}$ & 0.261 & 0.303 & 0.409 & 0.245 & 0.317 \\
\hline There are people who accept me. & 0.181 & 0.058 & 0.252 & 0.677 & 0.327 \\
\hline I can consult others about worries or problems. & 0.135 & 0.371 & 0.061 & 0.643 & 0.062 \\
\hline If I try, I can live while getting along with people & 0.295 & 0.395 & 0.242 & 0.600 & 0.144 \\
\hline
\end{tabular}




\begin{tabular}{|l|c|c|c|c|c|}
\hline & & & & \\
\hline Oround me. & 0.331 & 0.250 & 0.418 & 0.471 & 0.175 \\
\hline Others believe in my recovery. & 0.336 & 0.242 & 0.053 & 0.450 & 0.523 \\
\hline There is a place for me to spend leisure time. & 0.199 & 0.312 & 0.176 & 0.298 & 0.479 \\
\hline I can seek necessary information on my own. & 0.321 & 0.408 & 0.324 & 0.196 & 0.461 \\
\hline When I want to do something, I know how to do it. & 0.386 & 0.217 & 0.303 & 0.261 & 0.393 \\
\hline $\begin{array}{l}\text { I will be accepted by society even if I do not hide my } \\
\text { illness. }\end{array}$ & & & \\
\hline
\end{tabular}

Table 3. Results of the factor analysis of the SESP10

\begin{tabular}{|c|c|c|c|c|}
\hline Item & Factor 1 & Factor 2 & Factor 3 & Factor 4 \\
\hline \multicolumn{5}{|l|}{ I. Trust of Social Self } \\
\hline In the future, I can live a life that will satisfy myself. & 0.330 & 0.273 & 0.773 & 0.306 \\
\hline If I try, I have the power to change society. & 0.241 & 0.416 & 0.466 & 0.204 \\
\hline \multicolumn{5}{|l|}{ II. Self Management } \\
\hline I can control my physical condition in my daily life. & 0.887 & 0.251 & 0.201 & 0.234 \\
\hline I can control my mood in my daily life. & 0.631 & 0.294 & 0.303 & 0.230 \\
\hline I have the physical strength to live as I would like. & 0.487 & 0.299 & 0.270 & 0.359 \\
\hline \multicolumn{5}{|l|}{ III. Social Adaptability } \\
\hline I can seek necessary information on my own. & 0.187 & 0.256 & 0.173 & 0.688 \\
\hline When I want to do something, I know how to do it. & 0.393 & 0.203 & 0.313 & 0.538 \\
\hline \multicolumn{5}{|l|}{ IV. Mutual Support } \\
\hline There are people who accept me. & 0.135 & 0.754 & 0.150 & 0.284 \\
\hline Others believe in my recovery. & 0.325 & 0.584 & 0.291 & 0.214 \\
\hline I can consult others about worries or problems. & 0.343 & 0.538 & 0.195 & 0.115 \\
\hline
\end{tabular}

\subsection{Assessment of the reliability of the SESP10}

The Cronbach's a coefficient was calculated for the total and each subscale of the SESP10, to assess its internal consistency (Table 4). The a coefficients for the total and each subscale of the SESP10 were 0.7 or greater, indicating good internal consistency.

In order to assess the test-retest reliability of the SESP10, we calculated scores on the SESP10 separately for the first and second SESP tests and then calculated the correlation coefficients between the scores on the first and second tests. All of the correlation coefficients were significant at the $1 \%$ level, thus confirming the test-retest reliability (Table 5).

Table 4. a coefficients for the whole scale and each subscale of the SESP10

\begin{tabular}{|l|c|}
\hline SESP10 & Cronbach's a \\
\hline Total & 0.905 \\
\hline I. $\quad$ Trust of Social Self & 0.752 \\
\hline II. Self Management & 0.839 \\
\hline III. Social Adaptability & 0.700 \\
\hline IV. Mutual Support & 0.786 \\
\hline
\end{tabular}

Table 5. Correlation coefficients between the first and second tests for the whole scale and each subscale of the SESP10

\begin{tabular}{|c|c|}
\hline SESP10 & $\mathrm{R}$ \\
\hline \multicolumn{1}{|c|}{ Total } & $0.718^{* *}$ \\
\hline I. $\quad$ Trust of Social Self & $0.617^{* *}$ \\
\hline II. Self Management & $0.642^{* *}$ \\
\hline III. Social Adaptability & $0.496^{* *}$ \\
\hline IV. Mutual Support & $0.724^{* *}$ \\
\hline
\end{tabular}

${ }^{* *} p<0.01$ 


\subsection{Assessment of the validity of the SESP10}

In order to assess the criterion validity of the SESP10, we calculated the correlation coefficients between it and the related scales (Table 6). Significant correlations were confirmed for all scales except for the "self-management" subscale and Norbeck's "social support" scale.

Table 6. Correlation coefficients between SESP10 and related scales

\begin{tabular}{|c|c|c|c|c|c|}
\hline \multirow[b]{2}{*}{ Measures } & \multicolumn{5}{|c|}{ SESP10 } \\
\hline & Total score & $\begin{array}{l}\text { I.Trust of } \\
\text { Social Self }\end{array}$ & $\begin{array}{c}\text { II.Self } \\
\text { Management }\end{array}$ & $\begin{array}{c}\text { III.Social } \\
\text { Adaptability }\end{array}$ & $\begin{array}{l}\text { IV.Mutual } \\
\text { Support }\end{array}$ \\
\hline $\begin{array}{l}\text { Rosenberg's Self- } \\
\text { Esteem Scale }\end{array}$ & $0.798^{* *}$ & $0.710^{*+}$ & $0.671^{\text {** }}$ & $0.713^{\text {*t }}$ & $0.661^{*+}$ \\
\hline $\begin{array}{l}\text { Norbeck's Social } \\
\text { Support Questionnaire }\end{array}$ & $0.207^{\star}$ & $0.294^{* *}$ & 0.014 & $0.178^{*}$ & $0.259^{* *}$ \\
\hline Sense of coherence & $0.510^{* *}$ & $0.400^{* *}$ & $0.415^{\text {t*t }}$ & $0.505^{* *}$ & $0.455^{* \star}$ \\
\hline GHQ12 & $0.437^{\text {t*t }}$ & $0.314^{* *}$ & $0.357^{\text {t+ }}$ & $0.469^{*+*}$ & $0.374^{* *+}$ \\
\hline Life satisfaction & $0.522^{* *}$ & $0.435^{\text {t* }}$ & $0.456^{\text {t* }}$ & $0.449^{* *}$ & $0.449^{* *+}$ \\
\hline Having any life goals & $0.334^{* * *}$ & $0.306^{*+1}$ & $0.248^{*+*}$ & $0.303^{*+*}$ & $0.293^{\text {*** }}$ \\
\hline
\end{tabular}

\section{Discussion}

In the present study, we simplified the original 27 -item version of the instrument to measure the self-efficacy (selfconfidence) in social participation of individuals with mental illness, and created an abridged 10-item version (SESP10) that can be widely applied to people with severe mental illness.

The confirmatory factor analysis showed that the SESP10 maintained the four-factor structure of the original scale, with sufficient content validity; "trust of social self" (2 items), "self-management" ( 3 items), "social adaptability" (2 items) and "mutual support" (3 items). Furthermore, it had excellent internal consistency, test-retest reliability, and criterion validity.

Because people with severe mental illness can now function better in their communities because of improved local mental health services, the SESP10 should be a useful instrument due to its convenience. Further investigation will be needed for broader utilization of the SESP10, including an assessment of its effectiveness in local mental health services and in examining the abilities of mentally ill individuals.

\section{References}

Amagai, M., Suzuki, M., Shibata, F., \& Tsai, T. (2012). Development of an instrument to measure self-efficacy for social participation of people with mental illness. Archives of psychiatric nursing 26, 240-248.

Maeda, K., Hata, T., \& Hata H. (2003). Reliability of social support for schizophrenia patients in day care and work centers (first report), and comparison with healthy people (Japanese). Seishin Igaku, 45, 525-534.

Niiro, M., \& Mori, T. (2001). Investigation of the reliability and validity of the Japanese version of General Health Questionnaire (GSQ-12) (Japanese). Seishin Igaku, 43, 431-436.

Rosenberg, M. (1965). Society and Adolescent Self Image. Princeton University Press, Princeton.

Togari, T., \& Yamazaki, Y. (2005). Examination of the reliability and factor validity of 13 -item five-point version Sense of Coherence Scale (Japanese). Minzoku Eisei 71(4), 168-182. 